\title{
Effect on mechanical properties and stress strain characteristics of normal and high strength concrete at elevated temperature
}

\author{
Patel V*, Singh B, Ojha PN, Mohapatra BN
}

\author{
National Council for Cement and Building Materials, 34, KM Stone, Delhi Mathura Road, NH-2, Ballabgarh, \\ Haryana. \\ * Corresponding Author: vikas.patel299@gmail.com
}

Received: 27-07-2020

Accepted: 10-10-2020

\begin{abstract}
High strength concrete (HSC) has some disadvantages such as brittleness and poor resistance to fire. Fire exposure affects the concrete in way that the disintegration of concrete starts and a severe surface spalling occurs at very high temperatures. Therefore, the structural behaviour or response to the load will change after fire exposure and the structural members may not behave as they were designed. Further, the basics of flexural design depend on the stress- strain response of the concrete which is also affected upon fire exposure. Hence, this study is carried out to provide useful input to aid the provision of a fire resistance for structural behaviour of concrete by investigating the effects on mechanical properties of concrete after exposure to high temperatures up to $600^{\circ} \mathrm{C}$ and establishing a stress-strain relationship. The concrete cylinders of size $100 \mathrm{~mm}$ x $200 \mathrm{~mm}$ were exposed to the temperature of $200^{\circ} \mathrm{C}, 400^{\circ} \mathrm{C}$ and $600^{\circ} \mathrm{C}$ after which the residual compressive strength, split tensile strength and flexural strength were recorded. For stress strain characteristics, $100 \times 200 \mathrm{~mm}$ cylinders with polypropylene fiber content of $0.5 \%$ by volume of concrete were subjected to temperature exposure of $600^{\circ} \mathrm{C}$ for durations of 1 hour. Curves for reduction factors of strength and stress strain characteristics after fire/elevated temperature exposure has been established. Just consideration of reduced strength for assessment after fire exposure will not serve the purpose as the change in load response and increased deformation capacity also needs to be addressed properly.
\end{abstract}

Key words: High strength concrete (HSC), Stress Strain Characteristics, Spalling of concrete, Polypropylene fiber.

\section{Introduction}

With the development of concrete technology, HSC has been commonly employed in many concrete structures around the world. HSC offers more strength and durability compared to normal strength concrete (NSC) (Arora et al., 2016; 2017). But HSC also comes with the disadvantage of high brittleness and less fire endurance at elevated temperatures as compared to NSC. Mechanical properties of the concrete such as compressive strength, Modulus of Elasticity (MOE), stress strain relationship, etc. changes upon exposure to the elevated temperature (Phan and Carino, 1998). Also the structural behaviour of the concrete changes after exposure to elevated temperature which makes it important to study these parameters under fire exposure. In structures heat can come from many sources such as fire and prolonged high temperature on the exposed surface. Explosive spalling has been observed by many researchers often resulting in serious deterioration of the concrete. The absence of voids, which could relieve the continuous pressure build-up as a consequence of vaporization of evaporable water, may cause serious damage or even spalling to the concrete. Some plastic based fibers influence mechanical properties of concrete positively and may address the disadvantage of brittleness or poor resistance to fire (Guendouz et al., 2016). To reduce the risk of deterioration and spalling, previous literatures claimed that the use of fiber such as polypropylene and steel can have sufficient fire protection on the concrete structures. The initial moisture state of the concrete and the rate of heating may be the main parameters determining the effect of polypropylene fibers (Nishida and Yamazaki, 1995; Kalifa e al., 2001; Shihada, 2011). The emergence of polypropylene fibers has introduced to the world the possibility of having a highperformance and more cost-effective product in the market place. Polypropylene fibers also 
possess better durability as plastic does not rust. It also contributes to the ease in handling as it weighs about one-fifth of an equivalent steel fiber.

Fire performance of structural members depends on the properties of the constituent materials; knowledge of high-temperature properties of concrete is critical for fire resistance assessment under performance-based codes (Kodur et al., 2008). The parameters that control concrete behavior are: compressive strength, tensile strength, peak strain, modulus of elasticity, creep strain, thermal conductivity, thermal strain, etc. that are nonlinear functions of temperature. Also, aggregate types of concrete influence the concrete behavior exposed to fire (Diederichs et al., 1987).

Studies conducted in past (Tolentino et al., 2002) on the effect of high temperature on the residual performance of Portland cement concretes using NSC and HSC and the test specimens were cast using the coarse aggregate, river sand as the fine aggregate and sulfonated melamine super plasticizer as water reducing admixture. Specimens were exposed up to $600^{\circ} \mathrm{C}$ for 2 hours and tested. The study indicated that the increase in temperature, though resulted in significant reduction in compressive strength was mere pronouncing on $\mathrm{HSC}$ than NSC. At $600^{\circ} \mathrm{C}$, the reduction in compressive strength of NSC was $58 \%$ while that in HSC was $69 \%$. The reduction in modulus of elasticity in NSC was $49 \%$ while that in HSC was $59 \%$ due to the structure of concrete transformed coarser in both cases. Studies in past (Ravindrarajah et al., 2002) have also indicated that the High-strength concrete, independent of the binder material type used, experiences weight loss and the relationship between the weight loss and maximum temperature is non-linear and the compressive and tensile strengths show noticeable losses (above $15 \%$ ) even at the temperature of $200^{\circ} \mathrm{C}$; and it is observed that the elastic modulus drops marginally by about $5 \%$.

Four types of HSC specimens were investigated, namely specimens made with siliceous and carbonate aggregate concrete; with and without steel fiber reinforcement. The strain corresponding to peak strength did not significantly change up to about $400^{\circ} \mathrm{C}$ for all four types of HSC. Above this temperature the strains, corresponding respectively to peak strength, increased considerably. The strains attained, corresponding to peak strength at $600^{\circ} \mathrm{C}$ and $800^{\circ} \mathrm{C}$, were twice and seven times the strain at room temperature (Cheng et al., 2004). The flexural strength of fly ash concrete under elevated temperatures was investigated (Potha Raju et al., 2004) using Ordinary Portland Cement (OPC), fine sand and coarse aggregate with $0,10 \%$, $20 \%$ and $30 \%$ fly ash and mixes with w/c $0.55,0.50$ and 0.45 respectively and cured for 28 days. Flexural strength tests were conducted on specimens exposing to three different temperatures of $100^{\circ} \mathrm{C}, 200^{\circ} \mathrm{C}, 250^{\circ} \mathrm{C}$ in addition to room temperature $\left(28^{\circ} \mathrm{C}\right)$, exposing the specimens to $1 \mathrm{hr}$, $2 \mathrm{hrs}$ and $3 \mathrm{hrs}$. The above investigations reported that the fly ash concrete showed consistently the same behavioral pattern as that of concrete without fly ash under elevated temperatures up to $250^{\circ} \mathrm{C}$ under flexure. The flexural strength of both concretes decreased with increase in temperature. Concretes with $20 \%$ fly ash replacement showed better performance than the concrete without fly ash, by retaining more of its strength. The maximum losses recorded in all mixes without fly ash were in the range of $10-39.4 \%$; in all mixes with $10 \%$ fly ash, they were 4 $31.7 \%$.

The change in shape of stress-strain curve and the value of strain at peak stress and ultimate strain changes the stress block parameters used for design of reinforced concrete (RC) members. These parameters are the fundamentals that governs the design philosophies and hence if the stress-strain response is affects by fire exposure than its impact on these parameters needs to be understood and studied (Singh et al., 2020).

The present study includes investigation of the effects on mechanical properties of concrete upon exposure to high temperatures up to $600^{\circ} \mathrm{C}$ and establishing a stress-strain relationship. In this study, NSC and HSC were exposed to high temperatures and stress-strain response was studied. The concrete cylinders of size $100 \mathrm{~mm}$ x $200 \mathrm{~mm}$ were exposed to the temperature of 
$200^{\circ} \mathrm{C}, 400^{\circ} \mathrm{C}$ and $600^{\circ} \mathrm{C}$ after which the residual compressive strength, split tensile strength and flexural strength were recorded. For stress-strain response $100 \times 200 \mathrm{~mm}$ cylinders with polypropylene fiber content of $0.5 \%$ by volume of concrete were subjected to temperature exposure of $600^{\circ} \mathrm{C}$ for durations of 1 hour. Polypropylene fibers were added to the concrete as HSC undergoes severe spalling sometimes even explosive blast upon exposure to high temperature. Addition of appropriate amount of polypropylene fibers will significantly improve the spalling resistance of the concrete which in turn improves the integrity of the concrete specimen so that the stress strain response can be recorded. Further, addition of polypropylene fibers has no effect on mechanical properties of concrete at room temperature and even after exposure to elevated temperatures (Patel et al., 2019). Dosage of the polypropylene fibers as $0.5 \%$ by volume of concrete is taken as per the previous work done and other literatures (Mydin and Soleimanzadeh, 2012; Bagherzadeh et al., 2012).

\section{Concrete Ingredients}

\subsection{Materials}

\subsubsection{Cementitious Material}

One brand of Ordinary Portland cement (OPC 53 Grade) with fly ash and silica fume are used in this study. The 3 days, 07 days and 28 days' compressive strength of cement OPC 53 Grade were $36.00 \mathrm{~N} / \mathrm{mm}^{2}, 45.50 \mathrm{~N} / \mathrm{mm}^{2}$ and $57.50 \mathrm{~N} / \mathrm{mm}^{2}$ respectively. Properties of cement along with fly ash and silica fume are given in Table 1.

Table 1. Physical, Chemical and Strength Characteristics of Cementitious Material

\begin{tabular}{|c|c|c|c|}
\hline Characteristics & OPC -53 Grade & Silica Fume & Fly Ash \\
\hline \multicolumn{4}{|l|}{ Physical Tests } \\
\hline Fineness $\left(\mathrm{m}^{2} / \mathrm{kg}\right)$ & 320.00 & 16701 & 403 \\
\hline Soundness Autoclave (\%) & 00.05 & - & - \\
\hline Soundness Le Chatelier (mm) & 1.00 & - & - \\
\hline Setting Time Initial (min.) \& (max.) & $\begin{array}{c}170.00 \& \\
220.00\end{array}$ & - & - \\
\hline Specific gravity & 3.16 & 2.24 & 2.2 \\
\hline \multicolumn{4}{|l|}{ Chemical Tests } \\
\hline Loss of Ignition (LOI) (\%) & 1.50 & 1.16 & 3.64 \\
\hline Silica $\left(\mathrm{SiO}_{2}\right)(\%)$ & 20.38 & 95.02 & 62.53 \\
\hline Iron Oxide $\left(\mathrm{Fe}_{2} \mathrm{O}_{3}\right)(\%)$ & 3.96 & 0.80 & 4.66 \\
\hline Aluminium Oxide $\left(\mathrm{Al}_{2} \mathrm{O}_{3}\right)$ & 4.95 & - & 23.58 \\
\hline Calcium Oxide (CaO) (\%) & 60.73 & - & 1.17 \\
\hline Magnesium Oxide (Mg0) (\%) & 4.78 & - & 0.50 \\
\hline Sulphate $\left(\mathrm{SO}_{3}\right)(\%)$ & 2.07 & - & 0.15 \\
\hline \begin{tabular}{|l|l} 
Alkalies (\%) & $\mathrm{Na}_{2} \mathrm{O} \& \mathrm{~K}_{2} \mathrm{O}$ \\
\end{tabular} & $0.57 \& 0.59$ & $0.73 \& 2.96$ & $0.06 \& 1.46$ \\
\hline Chloride $(\mathrm{Cl})(\%)$ & 0.04 & - & 0.009 \\
\hline IR (\%) & 1.20 & - & - \\
\hline Moisture (\%) & - & 0.43 & - \\
\hline
\end{tabular}

\subsubsection{Aggregates}

Crushed aggregate with a maximum nominal size of $20 \mathrm{~mm}$ was used as coarse aggregate and natural riverbed sand confirming to Zone II as per IS: 383 was used as fine aggregate. Their physical properties are given in Table 2. The petrographic studies conducted on coarse aggregate indicated that the aggregate sample is medium grained with a crystalline texture and partially weathered sample of granite. The major mineral constituents were quartz, biotite, plagioclase-feldspar and orthoclase-feldspar. Accessory minerals are calcite, muscovite, tourmaline and iron oxide. The petrographic studies of fine aggregate indicated that the 
minerals present in order of abundance are quartz, orthoclase-feldspar, hornblende, biotite, muscovite, microcline-feldspar, garnet, plagioclase-feldspar, tourmaline, calcite and iron oxide. For both the coarse aggregate and fine aggregate sample the strained quartz percentage and their Undulatory Extinction Angle (UEA) are within permissible limits. Feldspar grains are partially fractured and shattered. The quality of both coarse and fine aggregate is fair. The silt content in fine aggregate as per wet sieving method is 0.70 percent.

Table 2. Properties of Aggregates

\begin{tabular}{|c|c|c|c|c|}
\hline \multirow{2}{*}{ Property } & \multicolumn{2}{|c|}{ Granite } & \multirow{2}{*}{ Fine Aggregate } \\
\cline { 2 - 5 } \multicolumn{2}{|c|}{ Specific gravity } & $\mathbf{1 0} \mathbf{~ m m}$ & \\
\hline \hline \multicolumn{2}{|c|}{ Water absorption (\%) } & 2.83 & 2.83 & 2.64 \\
\hline & $20 \mathrm{~mm}$ & 0.3 & 0.3 & 0.8 \\
\cline { 2 - 5 } & $10 \mathrm{~mm}$ & 1 & 100 & 100 \\
\cline { 2 - 5 } & $4.75 \mathrm{~mm}$ & 0 & 2 & 100 \\
\cline { 2 - 5 } & $2.36 \mathrm{~mm}$ & 0 & 0 & 95 \\
\cline { 2 - 5 } Sieve & $1.18 \mathrm{~mm}$ & 0 & 0 & 87 \\
\cline { 2 - 5 } Analysis & $600 \mu$ & 0 & 0 & 38 \\
\cline { 2 - 5 } Percentage & $300 \mu$ & 0 & 0 & 10 \\
\cline { 2 - 5 } Passing (\%) & $150 \mu$ & 0 & 0 & 2 \\
\cline { 2 - 5 } & Pan & 0 & 0 & 0 \\
\cline { 2 - 5 } & $19,13,19$ & - & - \\
\hline \multicolumn{2}{|c|}{ Abrasion, Impact \& Crushing Value } & 29,25 & - & - \\
\hline \multicolumn{2}{|c|}{ Flakiness \% \& Elongation \% } & & & \\
\hline
\end{tabular}

\subsubsection{Water}

Water complying with requirements of IS: 456-2000 for construction purpose was used.

\subsubsection{Admixture}

Polycarboxylic group based superplasticizer for w/c ratio 0.20 and 0.36 and Naphthalene based for $\mathrm{w} / \mathrm{c}$ ratio 0.47 complying with requirements of Indian Standard: 9103 is used throughout the investigation.

\subsubsection{Polypropylene fiber (PP)}

Polypropylene (PP) is a thermoplastic polymer used in a wide variety of applications. It is produced via chain-growth polymerization from the monomer propylene. Properties of the fiber has been given in Table 3 .

Table 3. Properties of Polypropylene fiber

\begin{tabular}{|c|c|}
\hline Properties & Value \\
\hline Cut length (mm) & 12 \\
\hline Effective diameter (micron) & $25-40$ \\
\hline Specific gravity & $0.90-091$ \\
\hline Melting point ( $\left.{ }^{\circ} \mathrm{C}\right)$ & $160-165$ \\
\hline Elongation $(\%)$ & $20-60$ \\
\hline Alkaline stability & Very good \\
\hline Young's modulus (MPa) & $>4000$ \\
\hline
\end{tabular}

\subsection{Mix design details}

In this study, the two different mixes of w/c ratio 0.47 (for NSC) \& 0.2 (for HSC) using granite aggregate were studied for determining stress strain relationship of NSC and HSC at elevated temperature. The slump of the fresh concrete was kept in the range of 75-100 mm. A pre-study 
was carried out to determine the optimum superplasticizer dosage for achieving the desired workability based on the slump cone test as per Indian Standard. The mix design details of specimens are given in Table 4. Adjustment was made in mixing water as a correction for aggregate water absorption. For conducting studies, the concrete mixes were prepared in pan type concrete mixer. Before use, the moulds were properly painted with mineral oil, casting was done in three different layers and each layer was compacted on vibration table to minimize air bubbles and voids. After 24 hours, the specimens were demoulded from their respective moulds. The laboratory conditions of temperature and relative humidity were monitored during the different ages at $27 \pm 2{ }^{\circ} \mathrm{C}$ and relative humidity $65 \%$ or more. The specimens were taken out from the tank and allowed for surface drying and then tested in saturated surface dried condition.

Table 4. Concrete Mix Design Details for study done

\begin{tabular}{|c|c|c|c|c|c|}
\hline$w / c$ & $\begin{array}{l}\text { Total Cementitious Content } \\
{[\text { Cement C + Flyash (FA) + }} \\
\text { Silica Fume (SF)] }\left(\mathrm{Kg} / \mathrm{m}^{3}\right)\end{array}$ & $\begin{array}{l}\text { Water } \\
\text { Content } \\
\left(\mathrm{Kg} / \mathrm{m}^{3}\right)\end{array}$ & $\begin{array}{l}\text { Admixtur } \\
\text { e \% by } \\
\text { weight of } \\
\text { Cement }\end{array}$ & $\begin{array}{l}\text { Fine Aggregate } \\
\text { as \% of Total } \\
\text { Aggregate by } \\
\text { weight }\end{array}$ & $\begin{array}{l}\text { 28-Days } \\
\text { strength } \\
\text { concrete } \\
\left(\mathrm{N} / \mathbf{m m}^{2}\right)\end{array}$ \\
\hline 0.47 & 362( & & 1.00 & 35 & 45.72 \\
\hline 0.20 & $750(548+112+90)$ & 150 & 1.75 & 35 & 97.76 \\
\hline
\end{tabular}

\section{Experimental Program}

For mechanical properties study, NSC and HSC cylinders without polypropylene fibers of size $100 \mathrm{~mm} \times 200 \mathrm{~mm}$ were exposed to the temperature of $200^{\circ} \mathrm{C}, 400^{\circ} \mathrm{C}$ and $600^{\circ} \mathrm{C}$ after which the residual compressive strength, split tensile strength and flexural strength were recorded.

For fire exposure, concrete cylinders were placed in an electrical furnace with a rate of heating as $5^{\circ} \mathrm{C} / \mathrm{min}$ till the desired temperature is achieved and then exposure temperature was maintained for 1 hour. Cooling to room temperature was carried out in closed and disconnected furnace. Specimens are tested once they are at room temperature.

For stress-strain study, NSC and HSC cylindrical specimens of dimension $100 \times 200 \mathrm{~mm}$ with polypropylene fiber content of $0.5 \%$ by volume of concrete were subjected to temperature exposure of $600^{\circ} \mathrm{C}$ for durations of 1 hour. Polypropylene fibers were used as HSC undergoes severe surface spalling after fire exposure and surface strain using compressometer cannot be recorded on the cracked surface. Concrete without fibers undergoes severe spalling and sometimes even blast in the furnace itself as shown in the figure $1-4$. Therefore, $0.5 \%$ of polypropylene fibers by volume of concrete were used to improve the spalling resistance or the integrity of the concrete specimens after fire exposure. Grinding of the concrete cylinders is done to have a smooth surface and avoid any errors in stress strain response due to irregularities in surface texture. Controlled samples were than tested for stress-strain relationship.

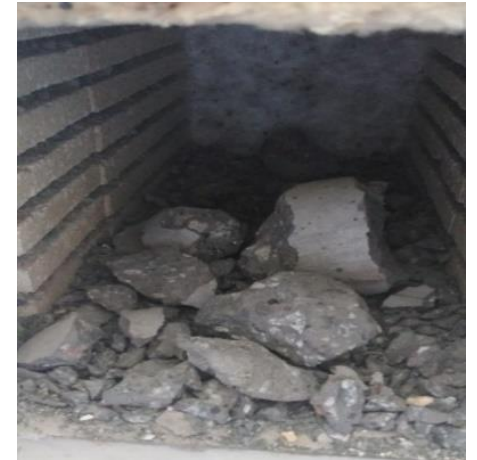

Fig. 1. Cylinder with control HSC mix after blast in furnace

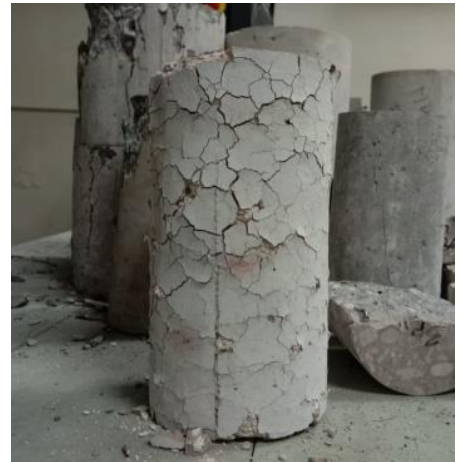

Fig. 2. Cylinder with control HSC mix with severe spalling 


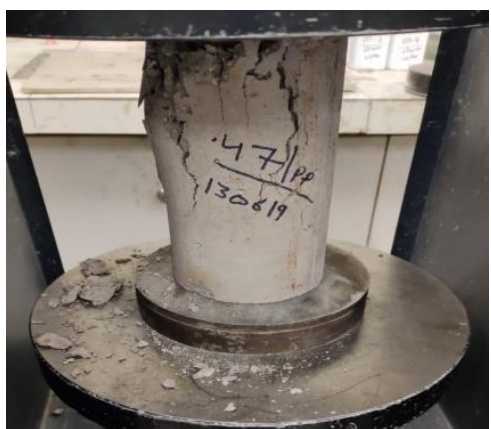

Fig. 3. NSC Cylinder with PP fiber after exposure to elevated temperature during testing

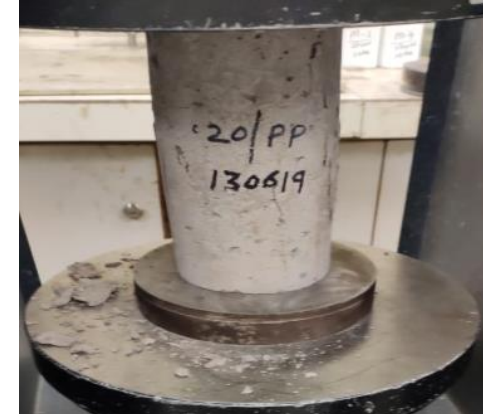

Fig. 4. HSC Cylinder with PP fiber after exposure to elevated temperature during testing

\section{Mechanical properties at elevated temperature}

Mechanical properties of the concrete are affected when exposed to elevated temperature depending on the exposed temperature. As the exposed temperature increases the concrete is deteriorated more severely. Reduction in compressive strength, split tensile strength and flexural strength upon fire exposure is expected and was also reported by many researchers in past.

The concrete cylinders of size $100 \mathrm{~mm} \times 200 \mathrm{~mm}$ were exposed to the temperature of $200^{\circ} \mathrm{C}$, $400^{\circ} \mathrm{C}$ and $600^{\circ} \mathrm{C}$ after which the residual compressive strength, split tensile strength and flexural strength were recorded. There after a qualitative relationship between ratio of residual strength to the controlled strength (strength at the temperature of $27^{\circ} \mathrm{C}$ ) has been plotted with respect to the exposed temperature (Figure 5 to figure 7). This will give an idea of the proportional reduction in strength upon elevated temperature exposure. For quantitative relationship between the reduction ratio and exposed temperature needs large sample data with a varied grades of strength so that an accurate and actual relationship can be developed for prediction. However, with these limited data, only qualitative variation can be predicted with an approximates values of reduction ratio.

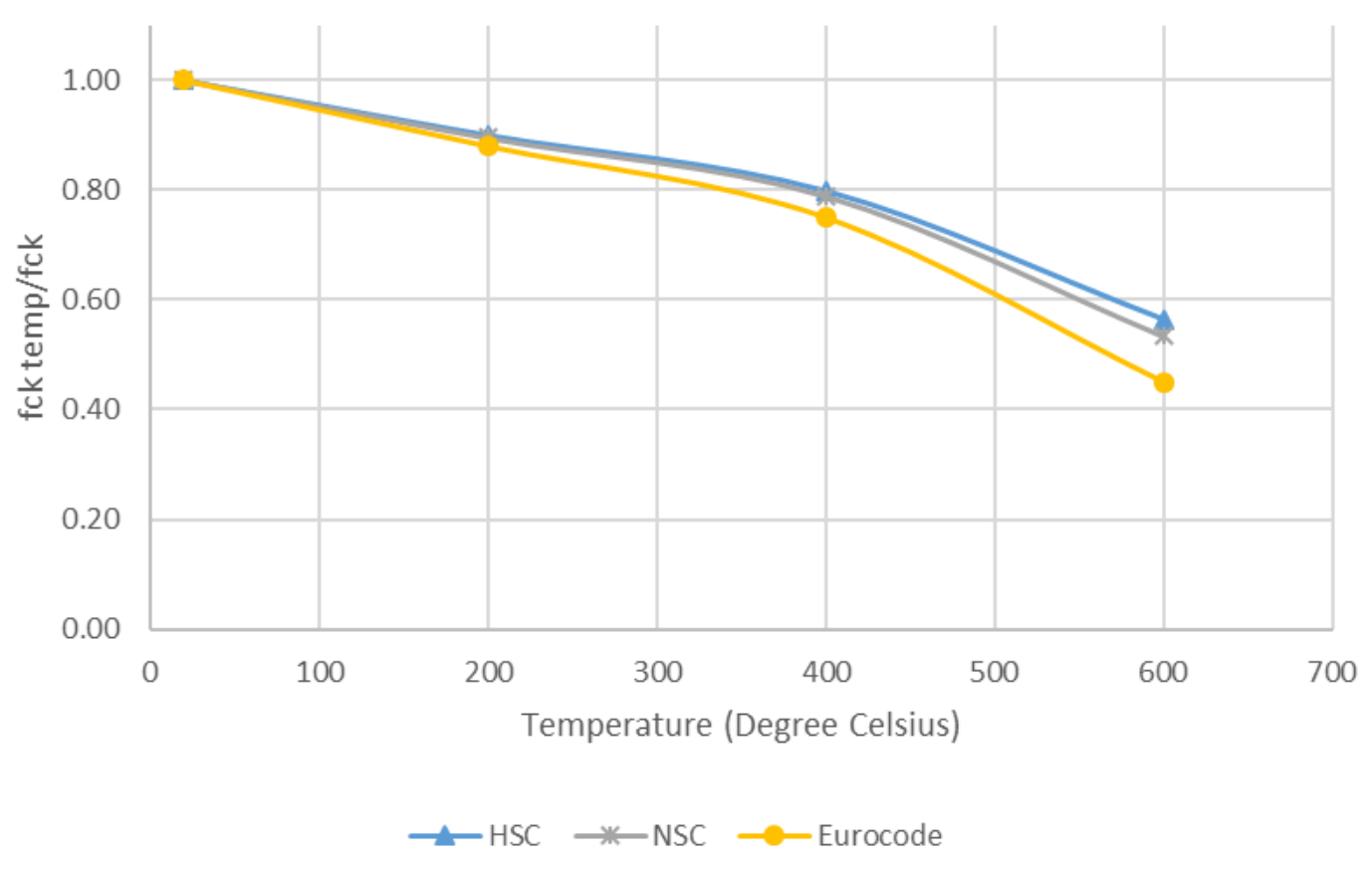

Fig. 5. Reduction of compressive strength with respect to elevated temperature exposure. 


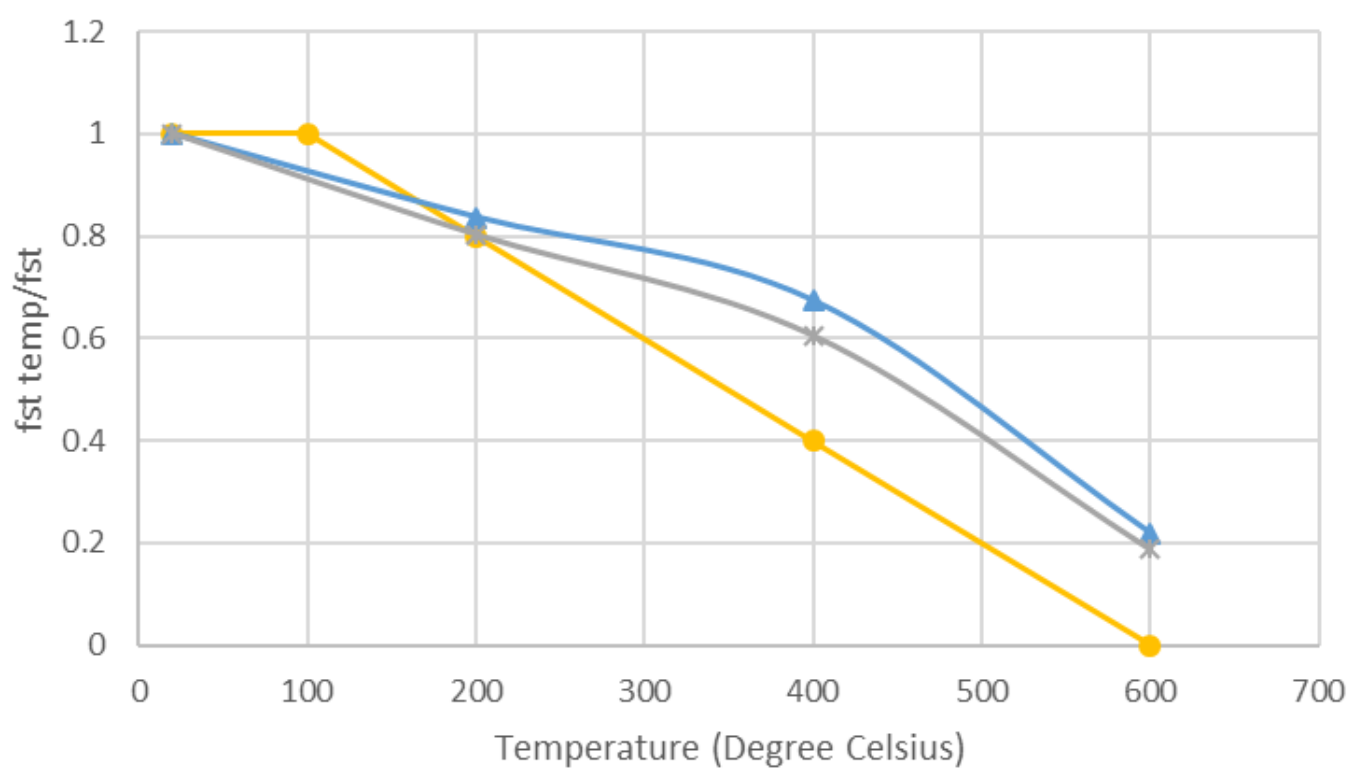

- Eurocode - HSC $\rightarrow$ NSC

Fig. 6. Reduction of split tensile strength with respect to elevated temperature exposure.

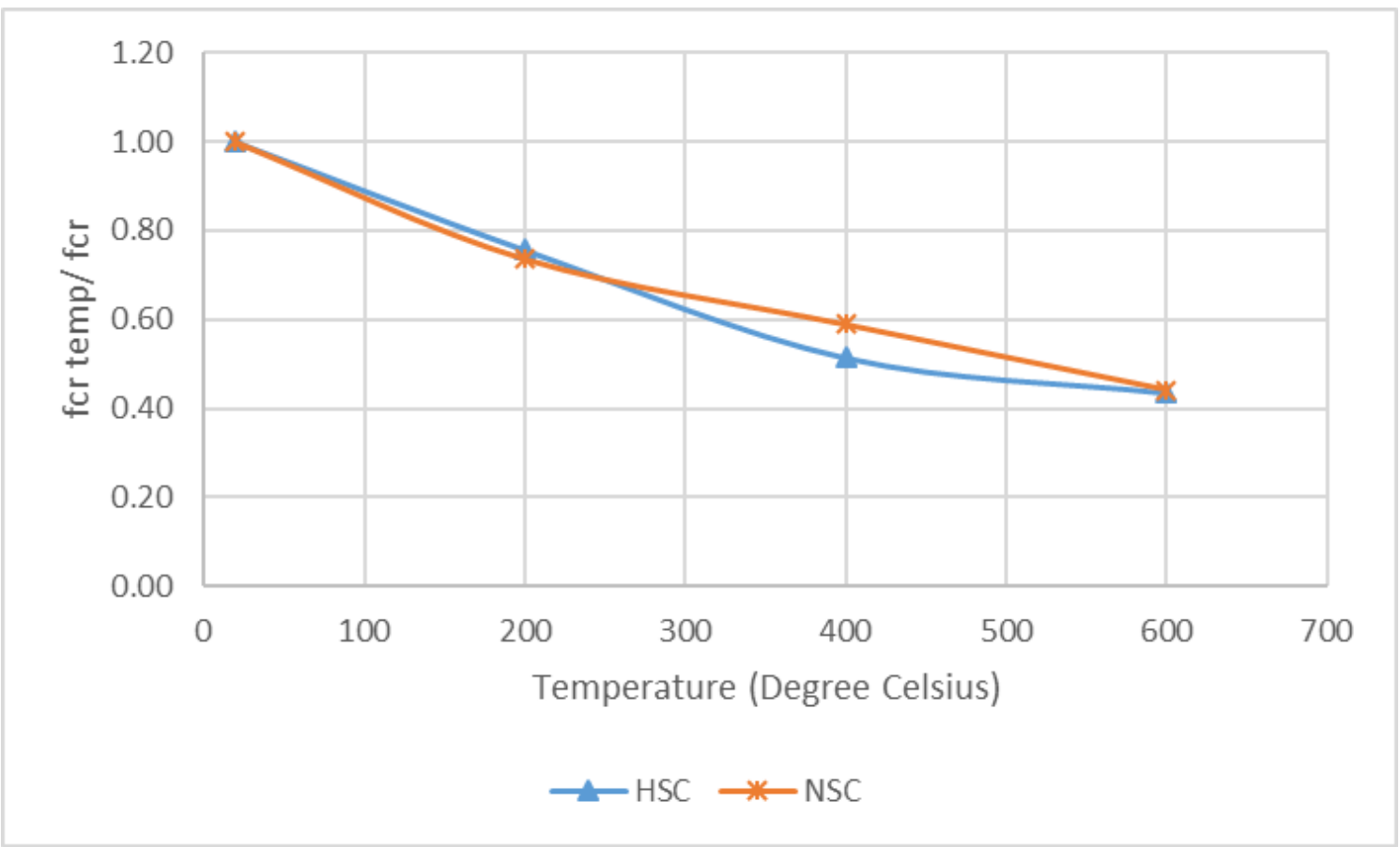

Fig. 7. Reduction of flexural strength with respect to elevated temperature exposure.

Above figures gives the variation of reduction ratios of compressive strength, split tensile strength and flexural strength with respect to temperature exposed. The reduction ratios are more or less same for both NSC and HSC. Further, above exposed temperature of $400^{\circ} \mathrm{C}$, the reduction ratio decreases at high rate. The experimental values are slightly higher than the values given by Eurocode up to the temperature exposure of $600^{\circ} \mathrm{C}$. Therefore, these curves can be used to have an approximate values of reduction ratios for concrete with indigenous materials. 


\section{Stress Stain Characteristics of Normal and High Strength Concrete at elevated temperature}

The concrete specimens were tested in a strain controlled compression testing machine of 3000 $\mathrm{kN}$ capacity (Figure-10-11) at room temperature of $27 \pm 2^{\circ} \mathrm{C}$ and relative humidity $65 \%$ or more. Two extensometers at the middle half of the height were used to get strain and two strains were averaged. To obtain a full stress vs strain curve, a rate of loading $0.4 \mu \mathrm{m} / \mathrm{sec}$ was adopted. The both ends of concrete cylinders were finished parallel by grinding and specimens with minimum surface texture cracks were selected (Figure 8-9). The representative stress-strain curve for normal and high strength concrete is shown below in Figure-12 to Figure 15. Experimental results indicate that the NSC strength concrete gradually fails after reaching its peak load, but the HSC suddenly explodes at peak load.

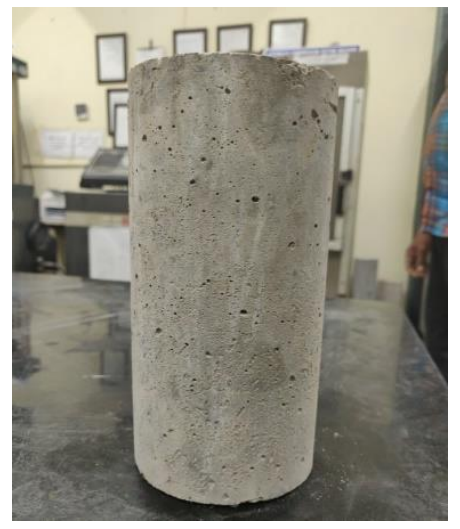

Fig. 8. Surface texture of concrete cylinder without exposure to elevated temperature

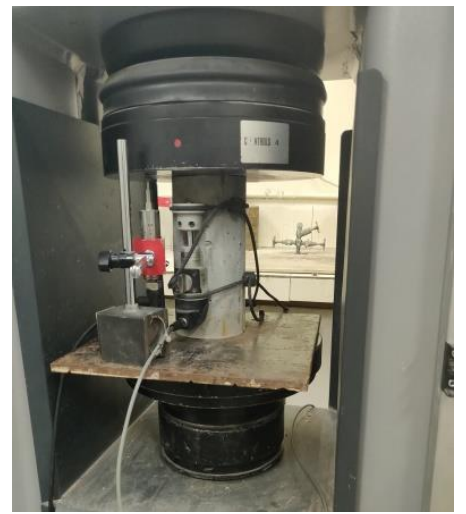

Fig. 10. Concrete cylinder under testing without elevated temperature exposure

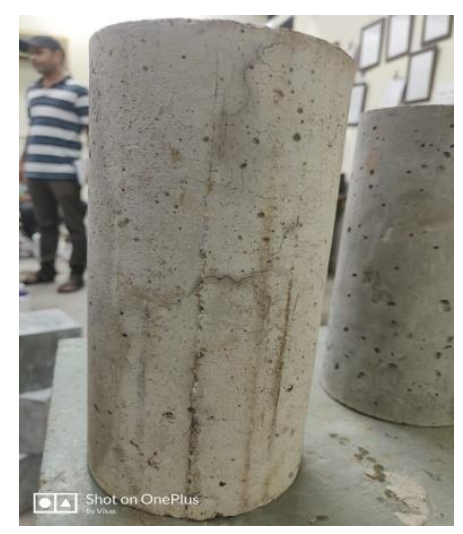

Fig. 9. Surface texture of concrete cylinder after exposure to $600^{\circ} \mathrm{C}$ for 1 hour duration

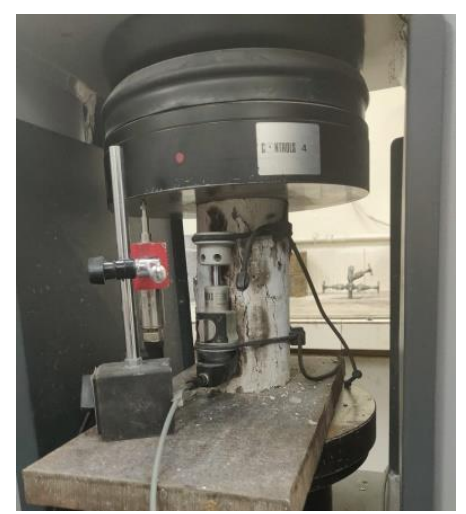

Fig. 11. Concrete cylinder under testing after exposure to $600^{\circ} \mathrm{C}$ for 1 hour duration

There is reduction in compressive strength upon exposure to elevated temperature which can be attributed to the reduction in effective cross-sectional area. Reduction in compressive strength is higher in case of HSC as compared to the NSC after same exposure to high temperature. Strain at peak stress and ultimate strain increases after exposure to elevated temperatures which can be attributed to the cracks found on the surface due to fire exposure. 


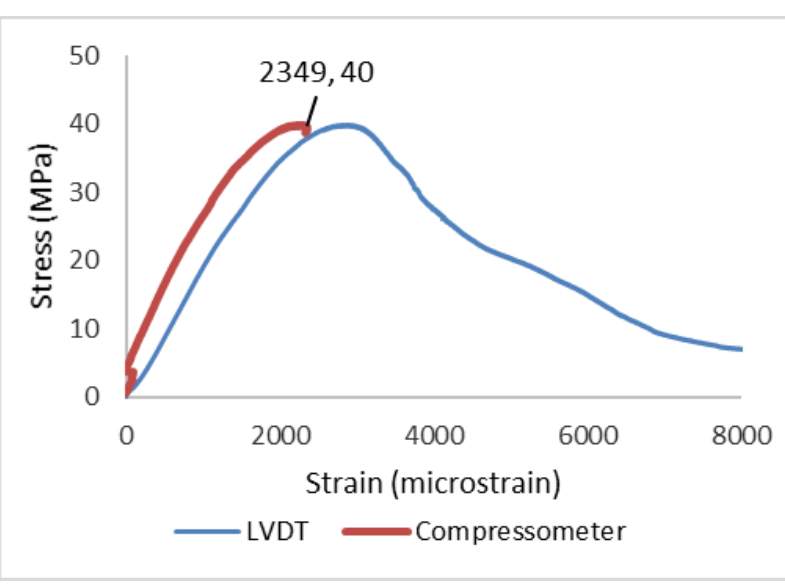

Fig. 12. Stress Strain Characteristics of NSC Experimentally determined for Controlled Sample

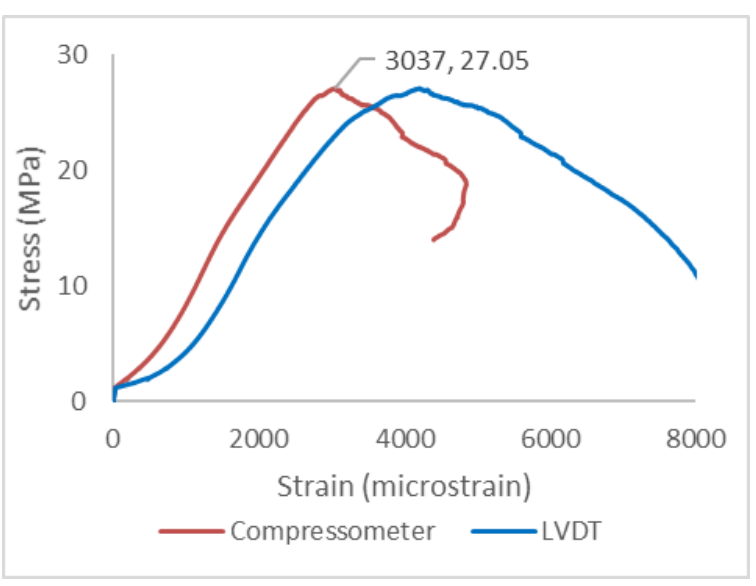

Fig.13. Stress Strain Characteristics of NSC Experimentally determined after Exposure to $600^{\circ} \mathrm{C}$ for 1 hour duration

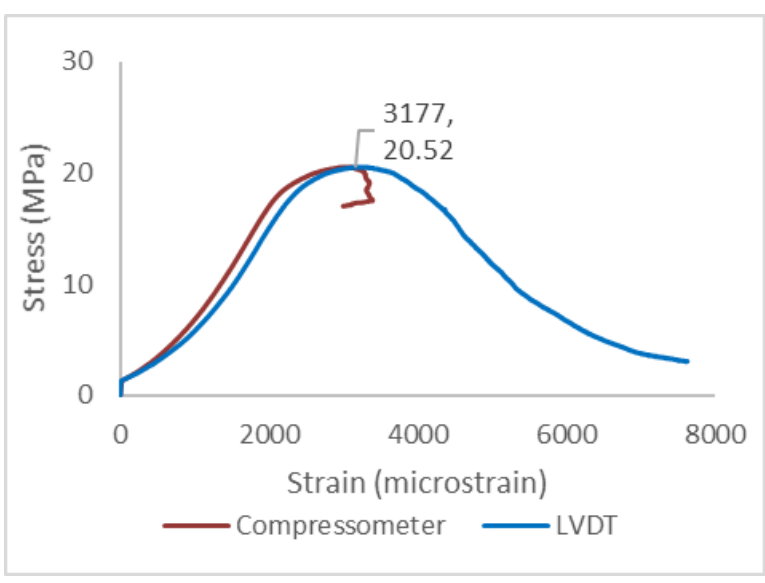

Fig. 15. Stress Strain Characteristics of HSC
Fig. 14. Stress Strain Characteristics of HSC

Experimentally determined for Controlled Sample

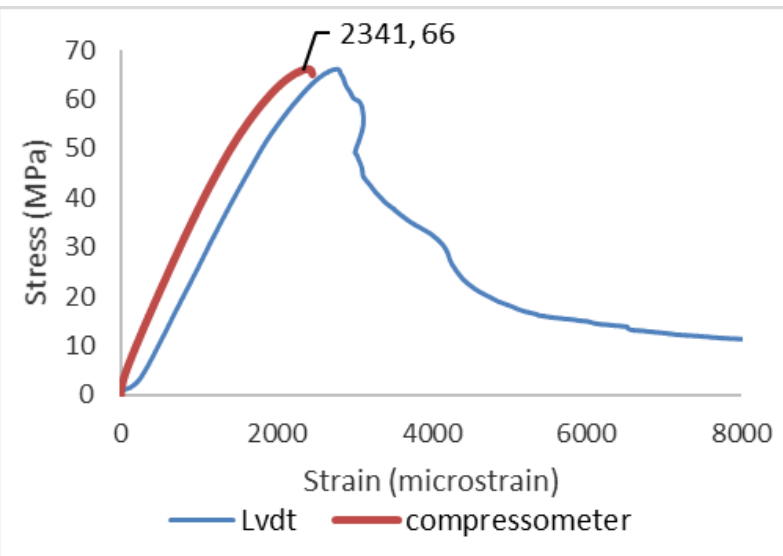

Experimentally determined after Exposure to $600^{\circ} \mathrm{C}$ for 1 hour duration

So there are two things going simultaneously, reduction in compressive strength and increase in strain at peak stress, ultimate strain. Also we know that strain values are higher for lower strength concrete and lower for HSC. The lower strain in HSC is due to its more compact packing, high density and less voids thus making it less susceptible to deformation. This is the reason HSC undergoes explosive failure as internal stresses generated are not dissipated through deformation and accumulation of large stresses leads to sudden failure.

After HSC is exposed to high temperatures, the micro cracks are generated in the concrete matrix some of which extends to the surface of the concrete. These micro cracks allow for the release of internal stresses and allows for deformation as the cracks expands upon load application. Therefore, the strain values increase after exposure to elevated temperatures.

\section{Conclusion}

From the study done, it can be said that the mechanical properties and structural behaviour of the concrete will be affected by fire exposure and this change observed is more in case of HSC. This is due to the significant reduction in compressive strength and increase in strain values. The compressive strength, split tensile strength and flexural strength decreases with increase in exposed temperature. Also the reduction ratios decrease at higher rate above $400^{\circ} \mathrm{C}$ which can 
also be seen from experimental results. The experimental values are slightly higher than the values given by Eurocode up to the temperature exposure of $600^{\circ} \mathrm{C}$. Therefore, these curves can be used to have an approximate values of reduction ratios for concrete with indigenous materials.

The shape of the stress strain curve also changes and becomes more parabolic after fire exposure as compared to the steeper curve for HSC which may lead to change in the stress block parameters that are fundamentals of flexural design. Hence, just consideration of reduced strength for assessment after fire exposure will not serve the purpose as the change in load response and increased deformation capacity also needs to be addressed properly. Further, quantification of the change in stress-strain parameters and the impact of these changes in the behaviour of structural member need to be studied so that safety and viability of the structure can be assessed.

\section{References}

Arora, V. V., Singh, B., \& Jain, S. (2016). Experimental studies on short term mechanical properties of high strength concrete. Indian Concrete Journal, 90(10), 65-75.

Arora, V. V., Singh, B., \& Jain, S. (2017). Effect of indigenous aggregate type on mechanical properties of high strength concrete. Indian Concr J, 91(1), 34-41.

Bagherzadeh, R., Pakravan, H. R., Sadeghi, A. H., Latifi, M., \& Merati, A. A. (2012). An investigation on adding polypropylene fibers to reinforce lightweight cement composites (LWC). Journal of Engineered Fibers and Fabrics, 7(4), 155892501200700410.

Cheng, F. P., Kodur, V. K. R., \& Wang, T. C. (2004). Stress-strain curves for high strength concrete at elevated temperatures. Journal of Materials in Civil Engineering, 16(1), 84-90.

Diederichs, U., Ehm, C., Weber, A., \& Becker, G. (1987). Deformation behaviour of HTR-concrete under biaxial stresses and elevated temperatures, Proceedings of the 9th International Conference on Structural Mechanics in Reactor technology, Lausanne (Switzerland), Vol H, paper h 2/3, Aug 17-21.

Guendouz, M., Debieb, F., Boukendakdji, O., Kadri, E. H., Bentchikou, M., \& Soualhi, H. (2016). Use of plastic waste in sand concrete. J. Mater. Environ. Sci, 7(2), 382-389.

Kalifa, P., Chene, G., \& Galle, C. (2001). High-temperature behaviour of HPC with polypropylene fibres: From spalling to microstructure. Cement and concrete research, 31(10), 1487-1499.

Kodur, V. K., Dwaikat, M. M. S., \& Dwaikat, M. B. (2008). High-temperature properties of concrete for fire resistance modeling of structures. ACI Materials Journal, 105(5), 517.

Mydin, M. A. O., \& Soleimanzadeh, S. (2012). Effect of polypropylene fiber content on flexural strength of lightweight foamed concrete at ambient and elevated temperatures. Advances in Applied Science Research, 3(5), 2837-2846.

Nishida, A. \& Yamazaki, N. (1995). Study on the properties of high strength concrete with short polypropylene fiber for spalling resistance, Proceedings of the International Conference on Concrete under Severe Conditions (CONSEC'95). Sapporo, Japan. August. E\&FN Spon, London, pp: 1141-1150.

Patel, V., Arora. V. V., Singh B., Kalra, M. \& Adhikari S. (2019). Study On Behavior of Polypropylene Fiber Reinforced High Strength Concrete Exposed to Higher Temperatures, $16^{\text {th }}$ NCB International Seminar

Phan, L. T., \& Carino, N. J. (1998). Review of mechanical properties of HSC at elevated temperature. Journal of Materials in Civil Engineering, 10(1), 58-65. 
Potha Raju, M., Shobha, M., \& Rambabu, K. (2004). Flexural strength of fly ash concrete under elevated temperatures. Magazine of Concrete Research, 56(2), 83-88.

Ravindrarajah, R. S., Lopez, R., \& Reslan, H. (2002). Effect of elevated temperature on the properties of high-strength concrete containing cement supplementary materials. In 9th International Conference on Durability of Building Materials and Components, Brisbane, Australia.

Shihada, S. (2011). Effect of polypropylene fibers on concrete fire resistance. Journal of civil engineering and management, 17(2), 259-264.

Singh, B., Patel, V., Ojha, P. N., \& Arora, V. V. (2020). Analysis of stress block parameters for high strength con-crete. Journal of Asian Concrete Federation, 6(1), 1-9.

Tolentino, E., Lameiras, F. S., Gomes, A. M., Silva, C. A., \& Vasconcelos, W. L. (2002). Effects of high temperature on the residual performance of Portland cement concretes. Materials research, 5(3), 301-307. 